Research Article

\title{
Treating Measurement Errors in the Run Rule Schemes Integrated with Shewhart $\bar{X}$ Chart
}

\author{
TingTing Shan $(\mathbb{D})$ and WeiDong Huang $(\mathbb{D}$ \\ School of Management, Nanjing University of Posts and Telecommunications, Nanjing, China \\ Correspondence should be addressed to TingTing Shan; stt@njupt.edu.cn
}

Received 15 April 2021; Revised 8 June 2021; Accepted 11 July 2021; Published 4 August 2021

Academic Editor: Kauko Leiviskä

Copyright ( 92021 TingTing Shan and WeiDong Huang. This is an open access article distributed under the Creative Commons Attribution License, which permits unrestricted use, distribution, and reproduction in any medium, provided the original work is properly cited.

In modern quality control applications, there often exist significant measurement errors because observations are measured quickly in time order. As a result, the errors influence the power of a control chart to detect a given change in the process parameter(s) of a quality characteristic. In this paper, by using a covariate error model, the properties of the Shewhart $\bar{X}$ chart integrated with run rules are investigated when errors exist in the measurement of quality characteristic. Two metrics, the average run length and 95\% quantile of the run length, are adopted to evaluate the chart's performance for different mean shifts and sample sizes. Numerous simulations are conducted, and the results indicate that the errors in the measurement significantly affect the performance of the run rule $\bar{X}$ chart, especially when the errors are large. To reduce this negative effect on the run rule $\bar{X}$ chart, measuring more times of each item in each subgroup and increasing the coefficient in the covariate error model are shown to be good choices for practitioners.

\section{Introduction}

As it is known in statistical process control (SPC), the Shewhart chart is effective in detecting large shifts in the process but is insensitive to small or moderate shifts. Even though the Shewhart-type charts still received much attention for the simple representation and implementation, as an intermediate solution, Western Electric [1] suggested the run rule scheme integrated with Shewhart-type charts to improve the chart's performance. Then, run rules combined with control charts were studied by many researchers, such as Divoky and Taylor [2]; Champ and Woodall [3]; Klein [4]; Fu et al. [5]; and so on. More recent works on control charts integrated with run rule schemes can be found in $\mathrm{Hu}$ and Castagliola [6]; Chew et al. [7]; Shongwe and Graham [8]; Shongwe and Graham [8]; Shongwe et al. [9]; Khaw and Chew [10]; Chew et al. [11]; Shongwe [12]; Malela-Majika and Rapoo [13]; MalelaMajika et al. [14]; Hu et al. [15]; and Ali et al. [16]. All these existing research studies focused on how to improve the chart's performance by incorporating run rules. They all assumed that observations are measured with no errors in the quality characteristic.

However, in the actual measuring equipment, an exact measurement of a quality characteristic is a rare phenomenon, causing measurement errors in practice. The properties of a control chart for monitoring observations with measurement errors differ from the chart for monitoring observations with precise measurements. Most existing works have only studied the measurement errors' effect on a specific monitoring scheme. For example, by using a linear covariate model, Linna and Woodall [17] investigated the measurement errors' effect on the Shewhart mean $(\bar{X})$ and variance $\left(S^{2}\right)$ charts. By extending the covariate model to the multivariate case, Linna et al. [18] studied the performance of multivariate control charts when measurement errors exist. Using the same linear model introduced in Linna and Woodall [17], the exponentially weighted moving average (EWMA) and cumulative sum (CUSUM) charts' performance for monitoring observations with measurement errors was studied in Maravelakis et al. [19] and Maravelakis [20]. More recently, considering the autocorrelation and 
measurement errors, Costa and Castagliola [21] studied the Shewhart $\bar{X}$ chart's performance and suggested a new skipping sampling technique to reduce the negative effect of autocorrelation. Hu et al. [22, 23] investigated the overall performance of the synthetic and VSS $\bar{X}$ chart when measurement errors exist. For a full account of publications on measurement errors prior to 2017, readers are referred to Maleki et al. [24]. For the most recent works on control charts with measurement errors, we suggest the research in Cheng and Wang [25]; Shongwe et al. [26]; Nguyen et al. [27]; Nguyen et al. [28]; Thanwane et al. [29]; Thanwane et al. [30]; and so on. Even the above research works are on the control charts with measurement errors. To the best of our knowledge, no research on the run rule schemes integrated with Shewhart $\bar{X}$ chart with measurement errors can be found.

In this paper, we focus on the properties of 2-of-3 run rules integrated with Shewhart-type charts in the presence of measurement errors. The run rule schemes are set by using warning limits, and it gives a signal when the selected run rule pattern occurs. This research can be extended to other run rule schemes, which are not presented here. It is noted that this paper is mainly to investigate the run rule $\bar{X}$ chart's performance when measurement errors exist, not to increase the chart's performance.

This paper is organized as follows. In Section 2, the linearly covariate error model used to represent the true value and the measurement value of observations is introduced. Then, the 2 -of- 3 run rule $\bar{X}$ chart under this measurement error model is presented in Section 3. The detailed effect of measurement errors on the run rule $\bar{X}$ chart is presented in Section 4. Finally, some conclusions and future research directions are given in Section 6.

\section{The Linearly Covariate Measurement Error Model}

In a process, $n \geq 1$ consecutive items $\left\{Y_{i, 1}, Y_{i, 2}, \ldots, Y_{i, n}\right\}$ of the quality characteristic $Y$ are collected at each sampling point $i=1,2, \ldots$. These items are assumed to be independent normal random variables with mean $\mu_{0}$ and standard deviation $\sigma_{0}$, i.e., $Y_{i, j} \sim N\left(\mu=\mu_{0}+\delta \sigma_{0}, \sigma_{0}\right)$. $\delta$ is the mean shift parameter in the process. Due to the measurement errors, the true value of quality characteristic $Y_{i, j}$ is observed from $m \geq 1$ measurements $\left\{X_{i, j, 1}, X_{i, j, 2}, \ldots, X_{i, j, m}\right\}$, with each $X_{i, j, k}$ being equal to the following equation:

$$
X_{i, j, k}=A+B Y_{i, j}+\varepsilon_{i, j, k},
$$

where $A$ and $B$ are two constants from the analysis of measurement device and $\varepsilon_{i, j, k} \sim N\left(0, \sigma_{M}\right)$ is an independent random error term.

In practice, if there are errors in the measurements of observations, it is suggested to measure each item several times and average these measurements for each item. By doing this, a smaller variance in the measurement error component than for a single measurement can be obtained. This can be simplified to the following equation:

$$
\bar{X}_{i}=\frac{1}{m n} \sum_{j=1}^{n} \sum_{k=1}^{m} X_{i, j, k}=A+\frac{1}{n}\left(B \sum_{j=1}^{n} Y_{i, j}+\frac{1}{m} \sum_{j=1}^{n} \sum_{k=1}^{m} \varepsilon_{i, j, k}\right),
$$

where $m$ is the number of measurements per item. It can be derived that the expection $E\left(\bar{X}_{i}\right)$ and the variance $V\left(\bar{X}_{i}\right)$ of $\bar{X}_{i}$,

$$
\begin{aligned}
& E\left(\bar{X}_{i}\right)=A+B\left(\mu_{0}+\delta \sigma_{0}\right), \\
& V\left(\bar{X}_{i}\right)=\frac{1}{n}\left(B^{2} \sigma_{0}^{2}+\frac{\sigma_{M}^{2}}{m}\right) .
\end{aligned}
$$

Moreover, considering that the measurement error variance $\sigma_{M}^{2}$ sometimes linearly depends on the process mean $\mu, \varepsilon$ is normally distributed with mean 0 and variance $\sigma_{M}^{2}=C+D \mu$, with two known constants $C$ and $D . E\left(\bar{X}_{i}\right)$ and $V\left(\bar{X}_{i}\right)$ are derived to be

$$
\begin{gathered}
E\left(\bar{X}_{i}\right)=A+B\left(\mu_{0}+\delta \sigma_{0}\right), \\
V\left(\bar{X}_{i}\right)=\frac{1}{n}\left(B^{2} \sigma_{0}^{2}+\frac{C+D \mu}{m}\right) .
\end{gathered}
$$

\section{The Shewhart $\bar{X}$ Chart Integrated with Run Rules under Linearly Covariate Measurement Errors}

Considering the constant measurement error variance in equations (3) and (4), by setting $\delta=0$ in the in-control state, two warning limits, LWL (the lower warning limit) and UWL (the upper warning limit), are given as follows:

$$
\begin{aligned}
\mathrm{LWL} & =A+B \mu_{0}-W \sqrt{\frac{1}{n}\left(B^{2} \sigma_{0}^{2}+\frac{\sigma_{M}^{2}}{m}\right)}, \\
\mathrm{UWL} & =A+B \mu_{0}+W \sqrt{\frac{1}{n}\left(B^{2} \sigma_{0}^{2}+\frac{\sigma_{M}^{2}}{m}\right)} .
\end{aligned}
$$

Second, considering the linearly increasing measurement error variance in equations (5) and (6), the warning limits of the chart are given as

$$
\begin{gathered}
\mathrm{LWL}=A+B \mu_{0}-W \sqrt{\frac{1}{n}\left(B^{2} \sigma_{0}^{2}+\frac{C+D \mu}{m}\right)}, \\
\mathrm{UWL}=A+B \mu_{0}+W \sqrt{\frac{1}{n}\left(B^{2} \sigma_{0}^{2}+\frac{C+D \mu}{m}\right)} .
\end{gathered}
$$

In the implementation of the Shewhart $\bar{X}$ chart integrated with 2-of-3 run rules, if two out of the three successive points fall above UWL or fall below LWL, an out-of-control signal is triggered. By modeling the 2-of-3 run rule chart with a Markov chain, Figure 1 shows all the transient states corresponding to the 2-of-3 run rules.

When a new sample is collected and the corresponding sample mean (point) falls into one of the above seven transient states or into the 8 th state, i.e., the absorbing state, 


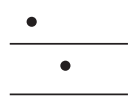

(a)

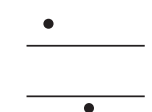

(b)

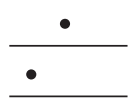

(c)

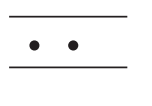

(d)

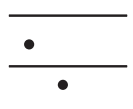

(e)

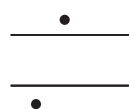

(f)

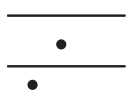

(g)

Figure 1: The transient states of 2-of-3 run rules. (a) (1). (b) (2). (c) (3). (d) (4). (e) (5). (f) (6). (g) (7).

where two out of the three successive points fall outside [LWL, UWL], then the run length properties of the Shewhart $\bar{X}$ chart integrated with 2 -of-3 run rules can be obtained by using the Markov chain matrix $\mathbf{P}$ :

$$
\mathbf{P}=\left(\begin{array}{cc}
\mathbf{Q} & \mathbf{r} \\
0^{T} & 1
\end{array}\right)=\left(\begin{array}{cccccccc}
0 & 0 & 0 & p_{C} & p_{L} & 0 & 0 & p_{U} \\
0 & 0 & 0 & 0 & 0 & 0 & p_{C} & p_{L}+p_{U} \\
p_{C} & p_{L} & 0 & 0 & 0 & 0 & 0 & p_{U} \\
0 & 0 & p_{U} & p_{C} & p_{L} & 0 & 0 & 0 \\
0 & 0 & 0 & 0 & 0 & p_{U} & p_{C} & p_{L} \\
p_{C} & 0 & 0 & 0 & 0 & 0 & 0 & p_{L}+p_{U} \\
0 & 0 & p_{U} & p_{C} & 0 & 0 & 0 & p_{L} \\
0 & 0 & 0 & 0 & 0 & 0 & 0 & 1
\end{array}\right),
$$

with the probabilities $p_{L}=P\left(\overline{X_{i}}<\mathrm{LWL}\right), p_{C}=P(\mathrm{LWL} \leq$ $\left.\overline{X_{i}} \leq \mathrm{UWL}\right)$, and $p_{U}=P\left(\overline{X_{i}}>\mathrm{UWL}\right)$. $\mathbf{Q}$ refers to the transient probabilities between 7 states in the figure and the vector $\mathbf{r}=1-\mathbf{Q} 1$, with $1=(1,1,1,1,1,1,1)^{T}$. For more details of the run rule charts, readers can refer to the related research works introduced in Section 1.

For the case in equations (3) and (4), the transient probabilities are equal to

$$
\begin{aligned}
p_{L}= & \Phi\left(-W-\frac{\delta \sqrt{n}}{\sqrt{1+\left(\gamma^{2} / B^{2} m\right)}}\right), \\
p_{C}= & \left(W-\frac{\delta \sqrt{n}}{\sqrt{1+\left(\gamma^{2} / B^{2} m\right)}}\right) \\
& -\Phi\left(-W-\frac{\delta \sqrt{n}}{\sqrt{1+\left(\gamma^{2} / B^{2} m\right)}}\right), \\
p_{U}= & \Phi\left(-W+\frac{\delta \sqrt{n}}{\sqrt{1+\left(\gamma^{2} / B^{2} m\right)}}\right),
\end{aligned}
$$

where $\gamma^{2}=\sigma_{M}^{2} / \sigma_{0}^{2}$ is the measurement error ratio and $\Phi(\cdot)$ is the cumulative distribution function (c.d.f.) of the standard normal distribution.

For the case in equations (5) and (6), the transient probabilities are equal to

$$
\begin{aligned}
p_{L}= & \Phi\left(\frac{-W \sqrt{B^{2} \sigma_{0}^{2}+\left(C+D \mu_{0} / m\right)}-B \delta \sigma_{0} \sqrt{n}}{\sqrt{B^{2} \sigma_{0}^{2}+(C+D \mu / m)}}\right), \\
p_{C}= & \Phi\left(\frac{W \sqrt{B^{2} \sigma_{0}^{2}+\left(C+D \mu_{0} / m\right)}-B \delta \sigma_{0} \sqrt{n}}{\sqrt{B^{2} \sigma_{0}^{2}+(C+D \mu / m)}}\right) \\
& -\Phi\left(\frac{-W \sqrt{B^{2} \sigma_{0}^{2}+\left(C+D \mu_{0} / m\right)}-B \delta \sigma_{0} \sqrt{n}}{\sqrt{B^{2} \sigma_{0}^{2}+(C+D \mu / m)}}\right), \\
p_{U}= & \Phi\left(\frac{-W \sqrt{B^{2} \sigma_{0}^{2}+\left(C+D \mu_{0} / m\right)}+B \delta \sigma_{0} \sqrt{n}}{\sqrt{B^{2} \sigma_{0}^{2}+(C+D \mu / m)}}\right) .
\end{aligned}
$$

From equations (10)-(15), it is shown that the parameter $A$ has no influence on the chart, while in practice, as it has been explained in Linna and Woodall [17], this parameter should be taken into account for the process location or the process capability.

Using the transition matrix $\mathbf{Q}$ in the Markov chain, the probability mass function (p.m.f.) $f_{L}(\ell \mid \mathbf{Q}, \mathbf{q})$ and the c.d.f. $F_{L}(\ell \mid \mathbf{Q}, \mathbf{q})$ of the run length distribution of the chart with measurement errors are given as

$$
\begin{aligned}
& f_{L}(\ell \mid \mathbf{Q}, \mathbf{q})=\mathbf{q}^{T} \mathbf{Q}^{\ell-1} \mathbf{r}, \\
& F_{L}(\ell \mid \mathbf{Q}, \mathbf{q})=1-\mathbf{q}^{T} \mathbf{Q}^{\ell} 1,
\end{aligned}
$$

with $\mathbf{q}=(0,0,0,1,0,0,0)^{T}$ being the initial probabilities of transient states.

Furthermore, the ARL of the chart can be derived as

$$
\mathrm{ARL}=\mathbf{q}^{T}(\mathbf{I}-\mathbf{Q})^{-1} 1,
$$

and the $\alpha \in(0,1)$ quantile $\mathrm{RL}_{\alpha}$ of the Shewhart $\bar{X}$ chart with 2 -of-3 run rules under linearly covariate measurement error model can be obtained as (see Gan [31])

$$
\begin{array}{r}
F_{L}\left(\mathrm{RL}_{\alpha}-1 \mid \mathbf{Q}, \mathbf{q}\right) \leq \alpha, \\
F_{L}\left(\mathrm{RL}_{\alpha} \mid \mathbf{Q}, \mathbf{q}\right)>\alpha .
\end{array}
$$

With equations (18) and (19), any quantile of the run length distribution can be computed. By setting $\alpha=0.95$, the $95 \%$ quantile $\mathrm{RL}_{0.95}$ of the run length distribution can be obtained. 


\section{Influence of Linearly Covariate Measurement Errors on the Run Rule Shewhart $\bar{X}$ Chart}

Some characteristics of run length are usually used to show the control chart's performance. Two metrics, ARL and $\mathrm{RL}_{0.95}$, are selected to evaluate the performance of the run rule $\bar{X}$ chart. As it has been stated in Khoo et al. [32], by computing a higher percentile of the run length distribution, say $\mathrm{RL}_{0.95}$ in this paper, a practitioner can state with $95 \%$ confidence that when a process shift $\delta=0.5$ occurs (see the case $\gamma^{2}=0, n=5$ in Table 1), a signal will be triggered by the 50th sample. The information from the percentiles of the run length acts as practical guidance to study the behavior of control charts. The subscripts "0" and " 1 " of ARL represent the corresponding in-control and out-of-control performance of the chart, respectively. Without loos of generality, it is assumed that $\mathrm{ARL}_{0}=370.4$. Consequently, the parameter $W$ of the run rule Shewhart $\bar{X}$ chart with linearly covariate measurement errors satisfies the following constraint:

$$
\operatorname{ARL}\left(m, n, B, \gamma^{2}, W, \delta=0\right)=\mathrm{ARL}_{0} .
$$

In this case, assuming $\delta=0$ in equations (10)-(15), we can compute the only value of $W$ using the "vert solvevert" function in MATLAB, irrespective of $m, n, B$, and $\gamma^{2}$.

4.1. A Constant Measurement Error Variance. It can be seen from equations (17)-(19) that $\mathrm{ARL}_{1}$ and $\mathrm{RL}_{0.95}$ are functions of $n, m, B, \gamma^{2}, W$, and $\delta$. Table 1 presents ARL and $\mathrm{RL}_{0.95}$ of the run rule $\bar{X}$ chart with linearly covariate error model for $\gamma^{2} \in\{0,0.1,0.2,0.3,0.5,0.7,1\}, \delta \in\{0.1,0.3$, $0.5,0.7,1,1.5,2\}$, and $n \in\{1,3,5,7$,$\} when m=1$ and $B=1$. The case $\gamma^{2}=0$ corresponds to the "no measurement error" case. For example, when $n=1, \gamma^{2}=0$, and $\delta=0$, the chart parameter $W=1.9293$. With this value, we have $\mathrm{ARL}=198.43$ and $\mathrm{RL}_{0.95}=591$ at $\delta=0.3$. As it can be seen from Table 1 , for a specified $\delta$, ARL and $\mathrm{RL}_{0.95}$ increase when the measurement error ratio $\gamma^{2}$ increases. This fact demonstrates the negative effect of the measurement errors on the run rule $\bar{X}$ chart. For instance, for the example above but with $\gamma^{2}=1$, we have ARL $=260.93$ and $\mathrm{RL}_{0.95}=778$. We can see that with the measurement error ratio increasing, larger $A R L$ and $\mathrm{RL}_{0.95}$ are needed to detect a shift.

The conclusions drawn above can also be seen from the four graphics in Figure 2 where ARL and $\mathrm{RL}_{0.95}$ are plotted for $\delta \in\{0.5,1.5\}, n \in\{1,3,5,7\}$ and $\gamma^{2}$ when $m=1$ and $B=1$. This figure confirms the conclusion that larger ARL and $\mathrm{RL}_{0.95}$ are observed with increasing measurement errors.

Table 2 presents ARL and $\mathrm{RL}_{0.95}$ of the chart for $B \in\{1,2,3,4,5\}, \delta \in\{0.1,0.3,0.5,0.7,1,1.5,2\}$, and $n \in\{1,3$, $5,7$,$\} when m=1$ and $\gamma^{2}=1$. It can be seen that for specified $\delta$ and $n$, the negative effect of measurement errors on the run rule $\bar{X}$ chart decreases as $B$ increases. Moreover, through the comparison between Tables 1 and 2, it can be seen that when $B=5$, the difference between ARL and SDRL corresponding to $\gamma^{2}=0$ (no measurement error) and $\gamma^{2}=1$ is negligible. For instance, when $\delta=0.3, m=1, \gamma^{2}=1, n=1$, and $B=5$
(Table 2), $\mathrm{ARL}=202.26$ and $\mathrm{RL}_{0.95}=602$, while in Table 1 , for the same values of $m$ and $\delta, \mathrm{ARL}=198.43$ and $\mathrm{RL}_{0.95}=$ 591 when $\gamma^{2}=0$.

In Figure 3, ARL and $\mathrm{RL}_{0.95}$ of the run rule $\bar{X}$ chart in the presence of measurement errors are plotted for $\delta \in\{0.5,1.5\}$, $n \in\{1,3,5,7\}$, and $B$ when $m=1$ and $\gamma^{2}=1$. This figure also confirms the conclusion that with the value of $B$ increasing, both ARL and $\mathrm{RL}_{0.95}$ decrease.

Table 3 presents ARL and $\mathrm{RL}_{0.95}$ for $m \in\{1,2,3,4,5\}$, $\delta \in\{0.1,0.3,0.5,0.7,1,1.5,2\}$, and $n \in\{1,3,5,7\}$ when $B=1$ and $\gamma^{2}=1$. It can be seen from Table 3 that as $m$ increases, the negative effect of the measurement errors on the run rule $\bar{X}$ chart decreases. For instance, for the case where $\delta=0.3$, $B=1, n=1$, and $\gamma^{2}=1, \mathrm{ARL}=260.93$ and $\mathrm{RL}_{0.95}=778$ decrease down to $\mathrm{ARL}=216.03$ and $\mathrm{RL}_{0.95}=643$, respectively, when $m=1$ increases up to $m=5$. So, it is concluded that if there is a relative high variability of the measurement error compared with the process variability, a large $m$ is needed to reduce the negative effect of measurement errors on the run rule $\bar{X}$ chart.

In Figure $4, \mathrm{ARL}$ and $\mathrm{RL}_{0.95}$ of the run rule $\bar{X}$ chart in the presence of measurement errors are plotted for $\delta \in\{0.5,1.5\}$, $n \in\{1,3,5,7\}$, and $m$ when $\gamma^{2}=1$ and $B=1$. This figure confirms the conclusion that by measuring the sample item several times, the negative effect of measurement errors on the run rule $\bar{X}$ chart can be reduced to some extent.

Since measuring the item in each sample several times can reduce the measurement errors' negative effect on control charts, the run length performance of run rule $\bar{X}$ chart with linearly covariate error is presented in Figure 5, for the case of $m=5$ measurements per item, using $\gamma^{2}$, $\delta \in\{0.5,1.5\}$ and $n \in\{1,3,5,7\}$ when $B=1$. It can be noted that for fixed $n$, with $m=5$ measurements per item, ARL and $\mathrm{RL}_{0.95}$ only have a slightly increasing trend with $\gamma^{2}$ increasing. Moreover, through the comparisons between the four graphics in Figure 2, the negative effect of measurement errors on the run rule $\bar{X}$ chart is reduced by taking multiple measurements of $m=5$, especially for the cases when $\gamma^{2} \geq 0.5$.

Finally, Figure 6 presents the run length performance of the run rule $\bar{X}$ chart for $B, \delta \in\{0.5,1.5\}$, and $n \in\{1,3,5,7\}$ when $\gamma^{2}=1$. From Figure 3, it is known that increasing $B$ reduces the negative effect of measurement errors on the run rule $\bar{X}$ chart. Meanwhile, through the comparison of Figures 3 and 6 , it is noted that taking $m=5$ measurements and increasing $B$ enable the negative effect of measurement errors on the run rule $\bar{X}$ chart to be diminished faster compared to the cases in Figure 3.

4.2. Linearly Increasing Measurement Error Variance. Considering the linearly increasing variance case, it can be seen that parameter $C$ in equations (5) and (6) behaves like $\sigma_{M}^{2}$ in equation (4). If there is a shift in the process mean, then it is amplified by parameter $D$, which also changes the variance of the measurement error. So, the influence of $D$ on the run rule $\bar{X}$ chart is investigated in Figure 7. In this figure, for specified values of $n \in\{1,3,5,7\}, B=1, C=5, m=1$, $\mu_{0}=10$, and $\sigma_{0}^{2}=10$ are set for illustration. Through this 
TABLE 1: Out-of-control $\left(\mathrm{ARL}, \mathrm{RL}_{0.95}\right) \quad$ when $\quad \mathrm{ARL}_{0}=370.4, \quad m=1, \quad$ and $\quad B=1 \quad$ for $\quad \gamma^{2} \in\{0,0.1,0.2,0.3,0.5,0.7,1\}$, $\delta \in\{0.1,0.3,0.5,0.7,1,1.5,2\}$, and $n \in\{1,3,5,7\}$.

\begin{tabular}{|c|c|c|c|c|c|c|c|}
\hline$\gamma^{2}$ & 0 & 0.1 & 0.2 & 0.3 & 0.5 & 0.7 & 1 \\
\hline$\delta$ & & & & $n=1$ & & & \\
\hline 0.1 & $(339.52,1013)$ & $(342.12,1021)$ & $(344.32,1028)$ & $(346.20,1033)$ & $(349.25,1042)$ & $(351.62,1050)$ & $(354.31,1058)$ \\
\hline 0.3 & $(198.43,591)$ & $(207.70,618)$ & $(216.03,643)$ & $(223.55,666)$ & $(236.60,705)$ & $(247.52,738)$ & $(260.93,778)$ \\
\hline 0.5 & $(100.86,299)$ & $(109.07,323)$ & $(116.82,346)$ & $(124.15,368)$ & $(137.66,409)$ & $(149.80,445)$ & $(165.86,493)$ \\
\hline 0.7 & $(53.16,156)$ & $(58.74,172)$ & $(64.17,189)$ & $(69.47,205)$ & $(79.62,235)$ & $(89.21,264)$ & $(102.57,304)$ \\
\hline 1 & $(23.30,66)$ & $(26.19,75)$ & $(29.10,84)$ & $(32.01,93)$ & $(37.82,110)$ & $(43.58,127)$ & $(52.03,152)$ \\
\hline 1.5 & $(8.38,22)$ & $(9.44,25)$ & $(10.53,28)$ & $(11.65,32)$ & $(13.98,39)$ & $(16.39,46)$ & $(20.12,57)$ \\
\hline 2 & $(4.33,10)$ & $(4.78,11)$ & $(5.26,13)$ & $(5.76,14)$ & $(6.81,17)$ & $(7.93,21)$ & $(9.71,26)$ \\
\hline$\delta$ & & & & $n=3$ & & & \\
\hline 0.1 & $(290.13,865)$ & $(296.08,883)$ & $(301.21,899)$ & $(305.67,912)$ & $(313.07,934)$ & $(318.95,952)$ & $(325.81,972)$ \\
\hline 0.3 & $(94.46,279)$ & $(102.41,303)$ & $(109.95,326)$ & $(117.10,347)$ & $(130.34,387)$ & $(153.17,455)$ & $(158.23,470)$ \\
\hline 0.5 & $(32.98,95)$ & $(36.86,107)$ & $(40.71,119)$ & $(44.53,130)$ & $(52.03,152)$ & $(59.32,174)$ & $(69.82,206)$ \\
\hline 0.7 & $(14.34,40)$ & $(16.19,45)$ & $(18.08,51)$ & $(19.99,57)$ & $(23.88,68)$ & $(27.83,80)$ & $(33.77,98)$ \\
\hline 1 & $(5.93,15)$ & $(6.63,17)$ & $(7.36,19)$ & $(8.12,21)$ & $(9.71,26)$ & $(11.37,31)$ & $(13.98,39)$ \\
\hline 1.5 & $(2.76,5)$ & $(2.96,6)$ & $(3.16,6)$ & $(3.38,7)$ & $(3.85,9)$ & $(4.36,10)$ & $(5.19,13)$ \\
\hline 2 & $(2.14,3)$ & $(2.19,3)$ & $(2.26,3)$ & $(2.33,3)$ & $(2.50,4)$ & $(2.68,5)$ & $(3.01,6)$ \\
\hline$\delta$ & & & & $n=5$ & & & \\
\hline 0.1 & $(252.34,752)$ & $(260.12,775)$ & $(266.95,796)$ & $(272.98,814)$ & $(283.15,844)$ & $(291.40,869)$ & $(301.21,899)$ \\
\hline 0.3 & $(58.13,171)$ & $(64.06,188)$ & $(69.82,206)$ & $(75.41,222)$ & $(86.08,254)$ & $(96.09,284)$ & $(109.95,326)$ \\
\hline 0.5 & $(17.62,50)$ & $(19.87,56)$ & $(22.15,63)$ & $(24.50,70)$ & $(29.10,84)$ & $(33.76,98)$ & $(40.71,119)$ \\
\hline 0.7 & $(7.55,20)$ & $(8.49,22)$ & $(9.46,25)$ & $(10.46,28)$ & $(12.54,34)$ & $(14.71,41)$ & $(18.08,51)$ \\
\hline 1 & $(3.49,7)$ & $(3.81,8)$ & $(4.15,9)$ & $(4.51,11)$ & $(5.26,13)$ & $(6.07,15)$ & $(7.36,19)$ \\
\hline 1.5 & $(2.17,3)$ & $(2.24,3)$ & $(2.31,3)$ & $(2.40,4)$ & $(2.59,5)$ & $(2.80,5)$ & $(3.16,1)$ \\
\hline 2 & $(2.01,2)$ & $(2.02,2)$ & $(2.03,2)$ & $(2.05,2)$ & $(2.09,3)$ & $(2.15,3)$ & $(2.26,3)$ \\
\hline$\delta$ & & & & $n=7$ & & & \\
\hline 0.1 & $(222.52,663)$ & $(231.30,689)$ & $(239.10,713)$ & $(246.07,733)$ & $(258.01,769)$ & $(267.85,799)$ & $(279.77,834)$ \\
\hline 0.3 & $(40.35,117)$ & $(44.89,131)$ & $(49.38,144)$ & $(53.79,158)$ & $(62.38,183)$ & $(70.63,208)$ & $(82.34,243)$ \\
\hline 0.5 & $(11.49,31)$ & $(12.97,36)$ & $(14.49,40)$ & $(16.04,45)$ & $(19.22,54)$ & $(22.47,64)$ & $(27.43,79)$ \\
\hline 0.7 & $(5.10,12)$ & $(5.67,14)$ & $(6.28,16)$ & $(6.90,18)$ & $(8.21,22)$ & $(9.60,26)$ & $(11.79,32)$ \\
\hline 1 & $(2.70,5)$ & $(2.88,6)$ & $(3.07,6)$ & $(3.28,7)$ & $(3.72,8)$ & $(4.20,10)$ & $(4.99,12)$ \\
\hline 1.5 & $(2.04,2)$ & $(2.07,3)$ & $(2.10,3)$ & $(2.13,3)$ & $(2.22,3)$ & $(2.33,3)$ & $(2.52,4)$ \\
\hline 2 & $(2.00,2)$ & $(2.00,2)$ & $(2.00,2)$ & $(2.01,2)$ & $(2.02,2)$ & $(2.03,2)$ & $(2.07,3)$ \\
\hline
\end{tabular}

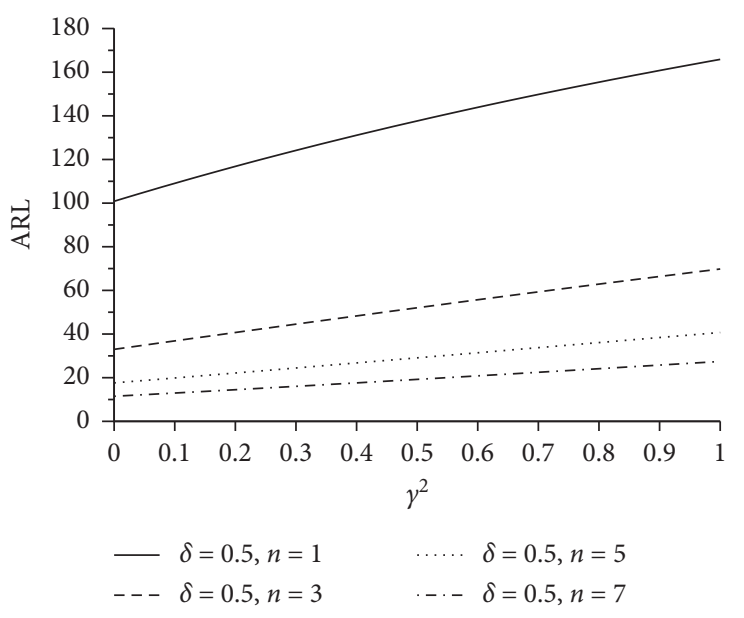

(a)

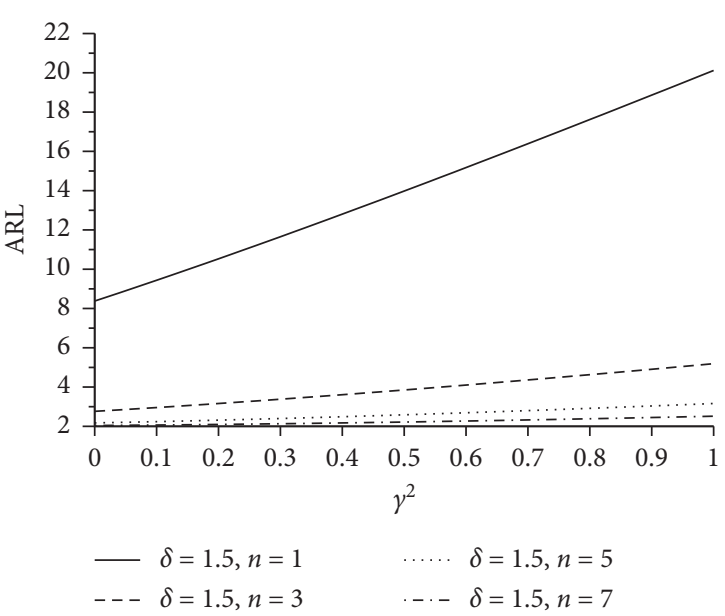

(b)

Figure 2: Continued. 


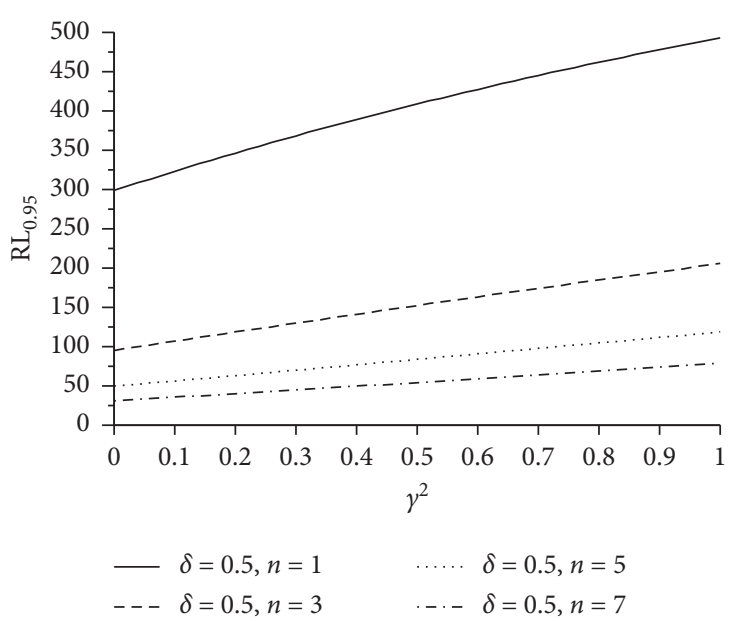

(c)

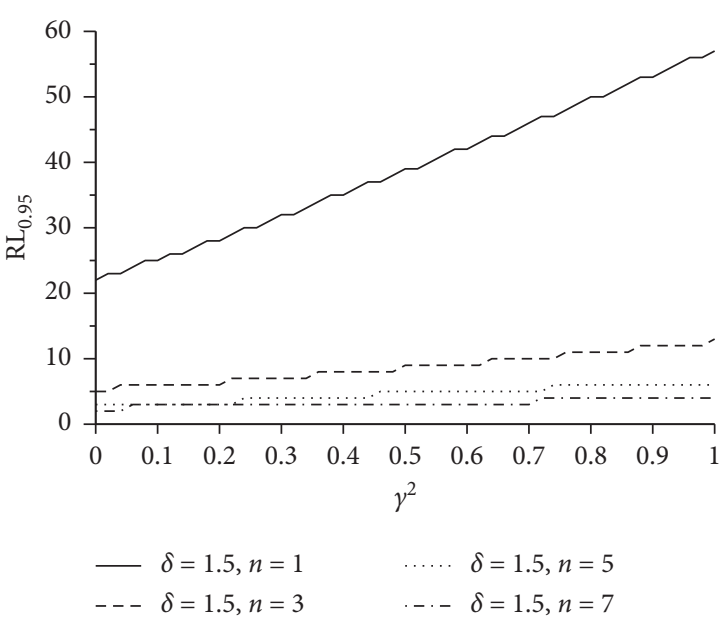

(d)

Figure 2: The influence of $\gamma^{2}$ on the run rule Shewhart $\bar{X}$ chart when $m=1, B=1, \delta \in\{0.5,1.5\}$, and $n \in\{1,3,5,7\}$.

TABLE 2: Out-of-control (ARL, $\mathrm{RL}_{0.95}$ ) when $A R L_{0}=370.4, m=1$, and $\gamma^{2}=1$ for $n \in\{1,3,5,7\}, \delta \in\{0.1,0.3,0.5,0.7,1,1.5,2\}$, and $B \in\{1,2,3,4,5\}$.

\begin{tabular}{|c|c|c|c|c|c|}
\hline$B$ & 1 & 2 & 3 & 4 & 5 \\
\hline$\delta$ & & & $n=1$ & & \\
\hline 0.1 & $(354.31,1058)$ & $(345.30,1031)$ & $(342.39,1022)$ & $(341.20,1018)$ & $(340.61,1017)$ \\
\hline 0.3 & $(260.93,778)$ & $(219.88,655)$ & $(208.67,621)$ & $(204.34,608)$ & $(202.26,602)$ \\
\hline 0.5 & $(165.86,493)$ & $(120.54,357)$ & $(109.95,326)$ & $(106.04,314)$ & $(104.20,309)$ \\
\hline 0.7 & $(102.57,304)$ & $(66.84,197)$ & $(59.35,174)$ & $(56.66,166)$ & $(55.41,162)$ \\
\hline 1.0 & $(52.03,152)$ & $(30.55,88)$ & $(26.51,76)$ & $(25.10,72)$ & $(24.45,70)$ \\
\hline 1.5 & $(20.12,57)$ & $(11.09,30)$ & $(9.56,26)$ & $(9.04,24)$ & $(8.80,23)$ \\
\hline 2.0 & $(9.71,26)$ & $(5.51,14)$ & $(4.84,12)$ & $(4.61,11)$ & $(4.51,11)$ \\
\hline$\delta$ & & & $n=3$ & & \\
\hline 0.1 & $(325.81,972)$ & $(303.51,905)$ & $(296.69,885)$ & $(293.95,877)$ & $(292.62,873)$ \\
\hline 0.3 & $(158.23,470)$ & $(113.57,337)$ & $(103.27,306)$ & $(99.48,294)$ & $(99.69,289)$ \\
\hline 0.5 & $(69.82,206)$ & $(42.63,124)$ & $(37.29,108)$ & $(35.41,103)$ & $(34.53,100)$ \\
\hline 0.7 & $(33.77,98)$ & $(19.03,54)$ & $(16.40,46)$ & $(15.49,43)$ & $(15.08,42)$ \\
\hline 1.0 & $(13.98,39)$ & $(7.74,20)$ & $(6.71,17)$ & $(6.37,16)$ & $(6.21,16)$ \\
\hline 1.5 & $(5.19,13)$ & $(3.27,7)$ & $(2.98,6)$ & $(2.88,6)$ & $(2.84,6)$ \\
\hline 2.0 & $(3.01,6)$ & $(2.29,3)$ & $(2.20,3)$ & $(2.17,3)$ & $(2.16,3)$ \\
\hline$\delta$ & & & $n=5$ & & \\
\hline 0.1 & $(301.21,899)$ & $(270.05,805)$ & $(260.93,778)$ & $(257.33,767)$ & $(255.58,762)$ \\
\hline 0.3 & $(109.95,326)$ & $(72.63,214)$ & $(64.70,190)$ & $(61.85,182)$ & $(60.52,178)$ \\
\hline 0.5 & $(40.71,119)$ & $(23.30,66)$ & $(20.12,57)$ & $(19.02,54)$ & $(18.51,52)$ \\
\hline 0.7 & $(18.08,51)$ & $(9.96,27)$ & $(8.59,23)$ & $(8.13,21)$ & $(7.92,21)$ \\
\hline 1.0 & $(7.36,19)$ & $(4.33,10)$ & $(3.85,9)$ & $(3.69,8)$ & $(3.62,8)$ \\
\hline 1.5 & $(3.16,6)$ & $(2.36,4)$ & $(2.25,3)$ & $(2.21,3)$ & $(2.20,3)$ \\
\hline 2.0 & $(2.26,3)$ & $(2.04,2)$ & $(2.02,2)$ & $(2.02,2)$ & $(2.01,2)$ \\
\hline$\delta$ & & & $n=7$ & & \\
\hline 0.1 & $(279.77,834)$ & $(242.68,723)$ & $(232.21,692)$ & $(228.13,680)$ & $(226.16,674)$ \\
\hline 0.3 & $(82.34,243)$ & $(51.59,151)$ & $(45.39,133)$ & $(43.19,126)$ & $(42.17,123)$ \\
\hline 0.5 & $(27.43,79)$ & $(15.26,43)$ & $(13.14,36)$ & $(12.41,34)$ & $(12.08,33)$ \\
\hline 0.7 & $(11.79,32)$ & $(6.59,17)$ & $(5.74,14)$ & $(5.46,13)$ & $(5.33,13)$ \\
\hline 1.0 & $(4.99,12)$ & $(3.17,6)$ & $(2.90,6)$ & $(2.81,5)$ & $(2.77,5)$ \\
\hline 1.5 & $(2.52,4)$ & $(2.11,3)$ & $(2.07,3)$ & $(2.06,3)$ & $(2.05,2)$ \\
\hline 2.0 & $(2.07,3)$ & $(2.01,2)$ & $(2.00,2)$ & $(2.00,2)$ & $(2.00,2)$ \\
\hline
\end{tabular}




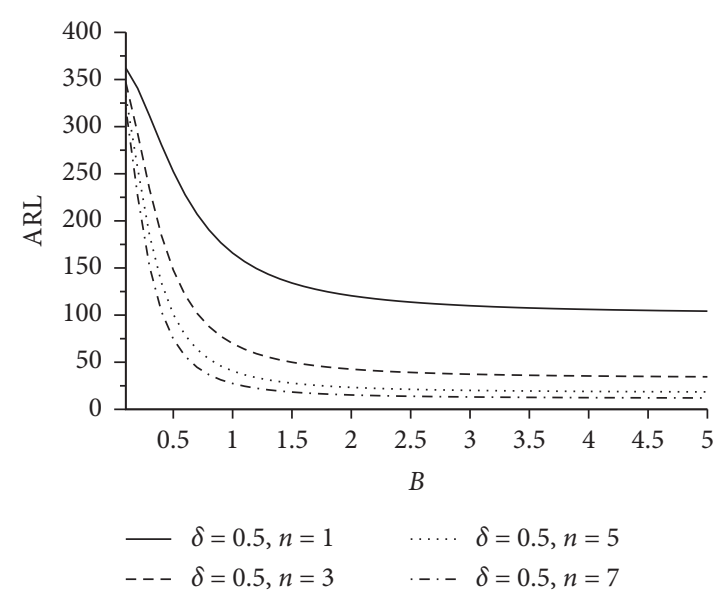

(a)

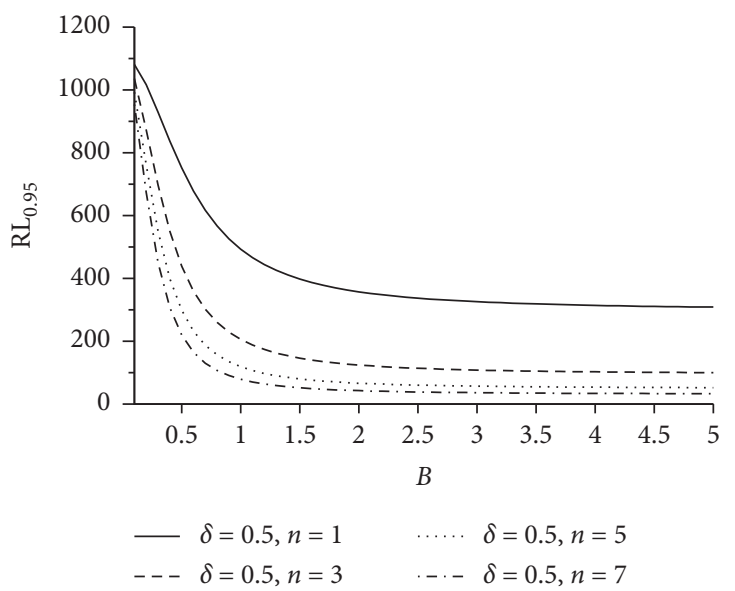

(c)

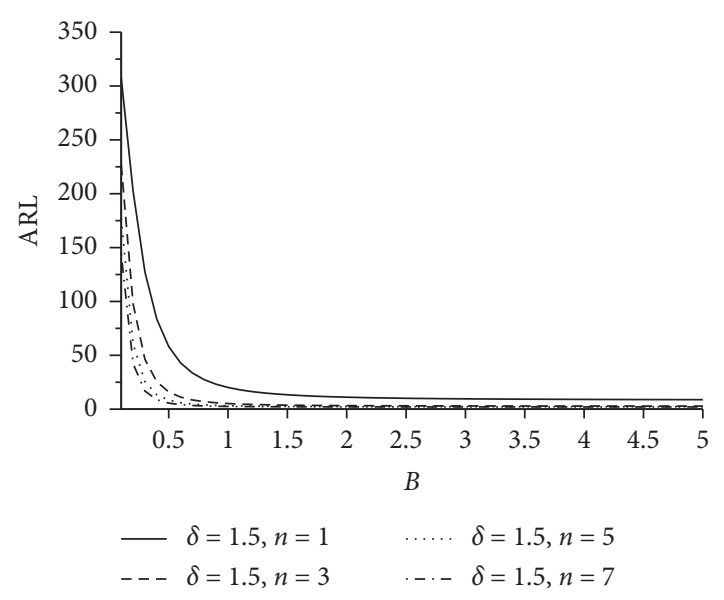

(b)

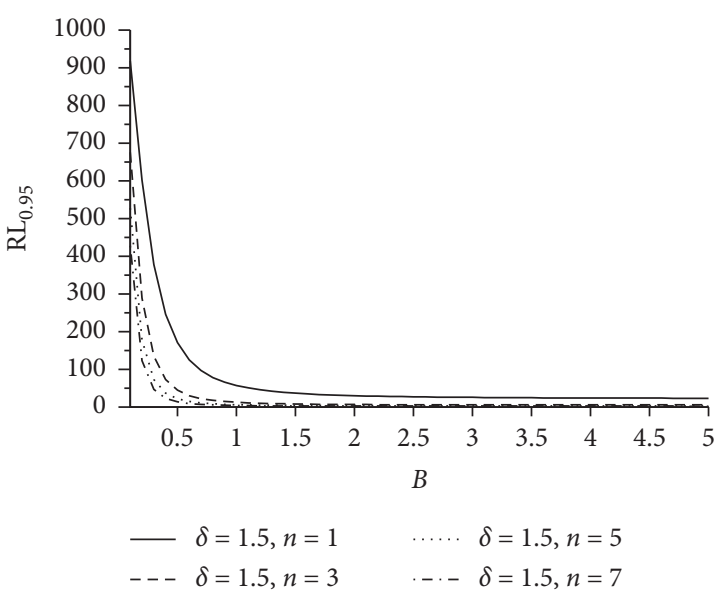

(d)

Figure 3: The influence of $B$ on the run rule Shewhart $\bar{X}$ chart when $m=1, \gamma^{2}=1, \delta \in\{0.5,1.5\}$, and $n \in\{1,3,5,7\}$.

TABle 3: Out-of-control (ARL, $\left.\mathrm{RL}_{0.95}\right)$ when $\mathrm{ARL}_{0}=370.4, B=1$, and $\gamma^{2}=1$ for $n \in\{1,3,5,7\}, \delta \in\{0.1,0.3,0.5,0.7,1,1.5,2\}$, and $m \in\{1,2,3,4,5\}$.

\begin{tabular}{|c|c|c|c|c|c|}
\hline$m$ & 1 & 2 & 3 & 4 & 5 \\
\hline$\delta$ & & & $n=1$ & & \\
\hline 0.1 & $(354.31,1058)$ & $(349.25,1042)$ & $(346.77,1035)$ & $(345.30,1031)$ & $(344.32,1028)$ \\
\hline 0.3 & $(260.93,778)$ & $(236.60,705)$ & $(225.90,673)$ & $(219.88,655)$ & $(216.03,643)$ \\
\hline 0.5 & $(165.86,493)$ & $(137.66,409)$ & $(126.51,375)$ & $(120.54,357)$ & $(116.82,346)$ \\
\hline 0.7 & $(102.57,304)$ & $(79.62,235)$ & $(71.20,210)$ & $(66.84,197)$ & $(64.17,189)$ \\
\hline 1.0 & $(52.03,152)$ & $(37.82,110)$ & $(32.98,95)$ & $(30.55,88)$ & $(29.10,84)$ \\
\hline 1.5 & $(20.12,57)$ & $(13.98,39)$ & $(12.03,33)$ & $(11.09,30)$ & $(10.53,28)$ \\
\hline 2.0 & $(9.71,26)$ & $(6.81,17)$ & $(5.93,15)$ & $(5.51,14)$ & $(5.26,13)$ \\
\hline$\delta$ & & & $n=3$ & & \\
\hline 0.1 & $(325.81,972)$ & $(313.07,934)$ & $(307.03,916)$ & $(303.51,905)$ & $(301.21,899)$ \\
\hline 0.3 & $(158.23,470)$ & $(130.34,387)$ & $(119.40,354)$ & $(113.57,337)$ & $(109.95,326)$ \\
\hline 0.5 & $(69.82,206)$ & $(52.03,152)$ & $(45.79,134)$ & $(42.63,124)$ & $(40.71,119)$ \\
\hline 0.7 & $(33.77,98)$ & $(23.88,68)$ & $(20.63,59)$ & $(19.03,54)$ & $(18.08,51)$ \\
\hline 1.0 & $(13.98,39)$ & $(9.71,26)$ & $(8.38,22)$ & $(7.74,20)$ & $(7.36,19)$ \\
\hline 1.5 & $(5.19,13)$ & $(3.85,9)$ & $(3.46,7)$ & $(3.27,7)$ & $(3.16,6)$ \\
\hline 2.0 & $(3.01,6)$ & $(2.50,4)$ & $(2.36,4)$ & $(2.29,3)$ & $(2.26,3)$ \\
\hline$\delta$ & & & $n=5$ & & \\
\hline 0.1 & $(301.21,899)$ & $(283.15,844)$ & $(274.83,820)$ & $(270.05,805)$ & $(266.95,796)$ \\
\hline 0.3 & $(109.95,326)$ & $(86.08,254)$ & $(77.23,228)$ & $(72.63,214)$ & $(69.82,206)$ \\
\hline
\end{tabular}


TABle 3: Continued.

\begin{tabular}{|c|c|c|c|c|c|}
\hline$m$ & 1 & 2 & 3 & 4 & 5 \\
\hline 0.5 & $(40.71,119)$ & $(29.10,84)$ & $(25.22,72)$ & $(23.30,66)$ & $(22.15,63)$ \\
\hline 0.7 & $(18.08,51)$ & $(12.54,34)$ & $(10.80,29)$ & $(9.96,27)$ & $(9.46,25)$ \\
\hline 1.0 & $(7.36,19)$ & $(5.26,13)$ & $(4.63,11)$ & $(4.33,10)$ & $(4.15,9)$ \\
\hline 1.5 & $(3.16,6)$ & $(2.59,5)$ & $(2.43,4)$ & $(2.36,4)$ & $(2.31,3)$ \\
\hline 2.0 & $(2.26,3)$ & $(2.09,7)$ & $(2.05,3)$ & $(2.04,2)$ & $(2.03,2)$ \\
\hline$\delta$ & & & $n=7$ & & \\
\hline 0.1 & $(279.77,834)$ & $(258.01,769)$ & $(248.23,740)$ & $(242.68,723)$ & $(239.10,713)$ \\
\hline 0.3 & $(82.34,243)$ & $(62.38,183)$ & $(55.24,162)$ & $(51.59,151)$ & $(49.38,144)$ \\
\hline 0.5 & $(27.43,79)$ & $(19.22,54)$ & $(16.57,46)$ & $(15.26,43)$ & $(14.49,40)$ \\
\hline 0.7 & $(11.79,32)$ & $(8.21,22)$ & $(7.11,18)$ & $(6.59,17)$ & $(6.28,16)$ \\
\hline 1.0 & $(4.99,12)$ & $(3.72,8)$ & $(3.35,7)$ & $(3.17,6)$ & $(3.07,6)$ \\
\hline 1.5 & $(2.52,4)$ & $(2.22,3)$ & $(2.15,3)$ & $(2.11,3)$ & $(2.10,3)$ \\
\hline 2.0 & $(2.07,3)$ & $(2.02,2)$ & $(2.01,2)$ & $(2.01,2)$ & $(2.00,2)$ \\
\hline
\end{tabular}

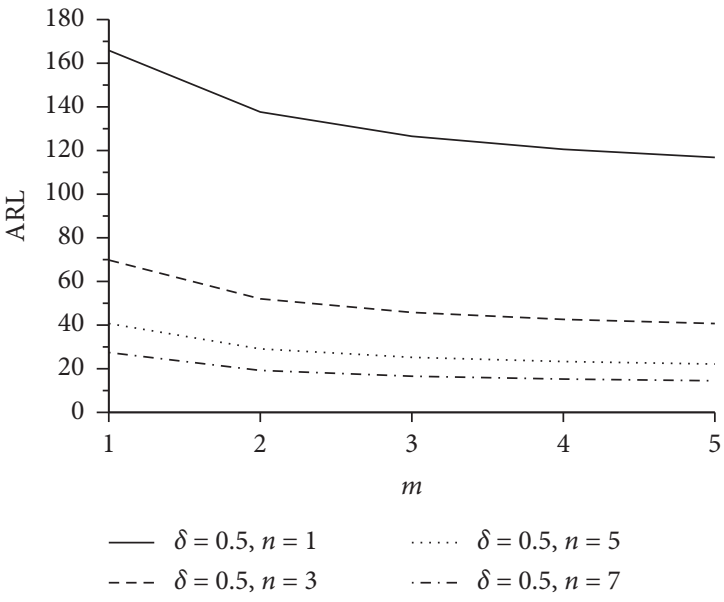

(a)

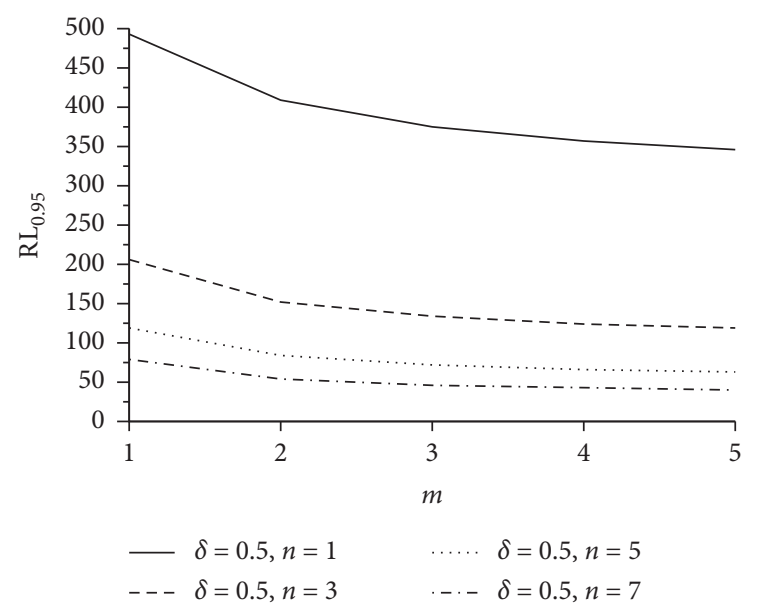

(c)

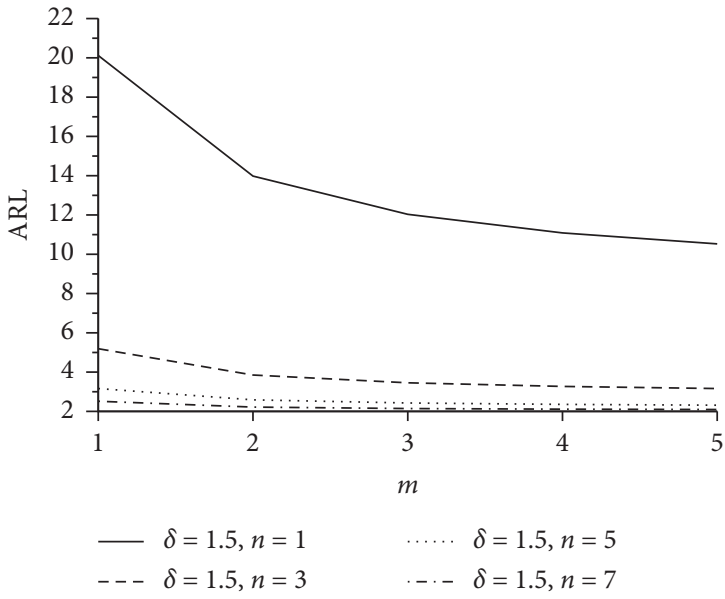

(b)

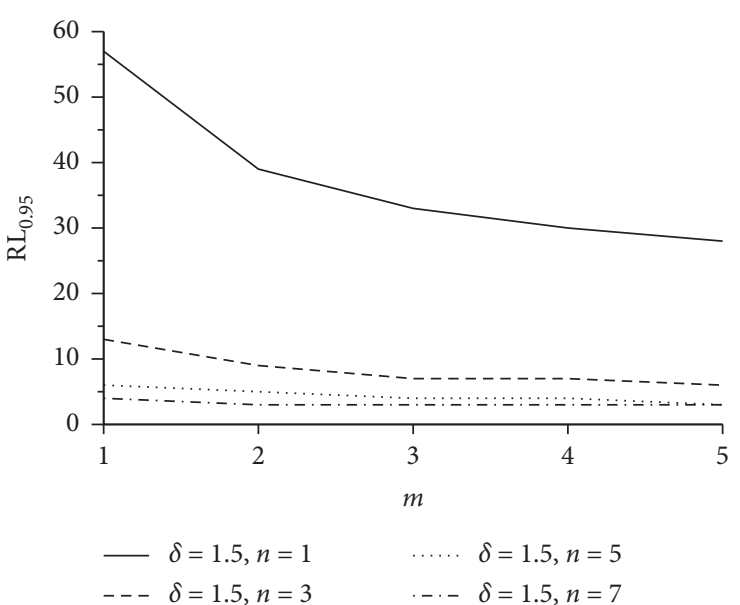

(d)

Figure 4: The effect of $m$ on the run rule Shewhart $\bar{X}$ chart when $B=1, \gamma^{2}=1, \delta \in\{0.5,1.5\}$, and $n \in\{1,3,5,7\}$.

figure, it is seen that increasing $D$ can significantly increase the values of $A R L$ and $R_{0.95}$. This fact indicates the negative effect of linearly increasing variance on the run rule $\bar{X}$ chart.
For instance, if $n=3$ and $\delta=0.5$, when $D=1$ increases up to $D=3, \mathrm{ARL}=74.80$ and $\mathrm{RL}_{0.95}=221$ increase up to $\mathrm{ARL}=104.61$ and $\mathrm{RL}_{0.95}=310$, respectively. 


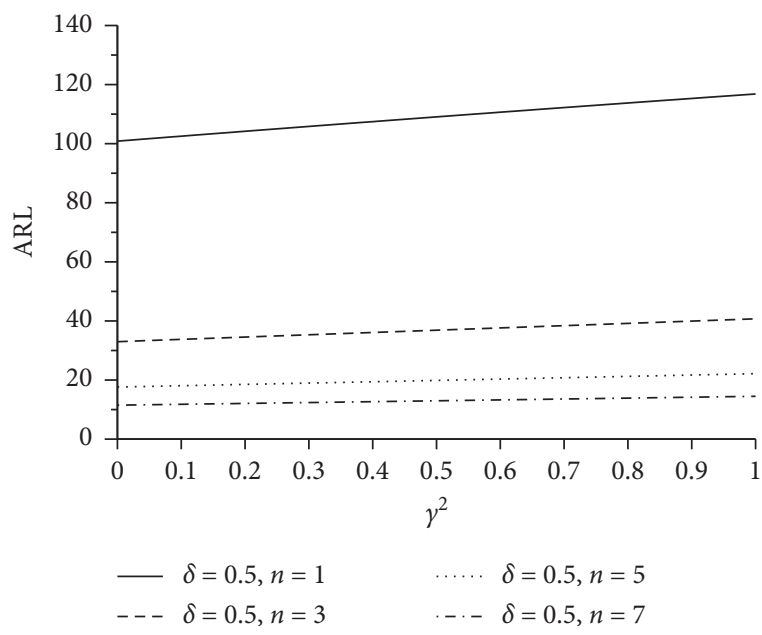

(a)

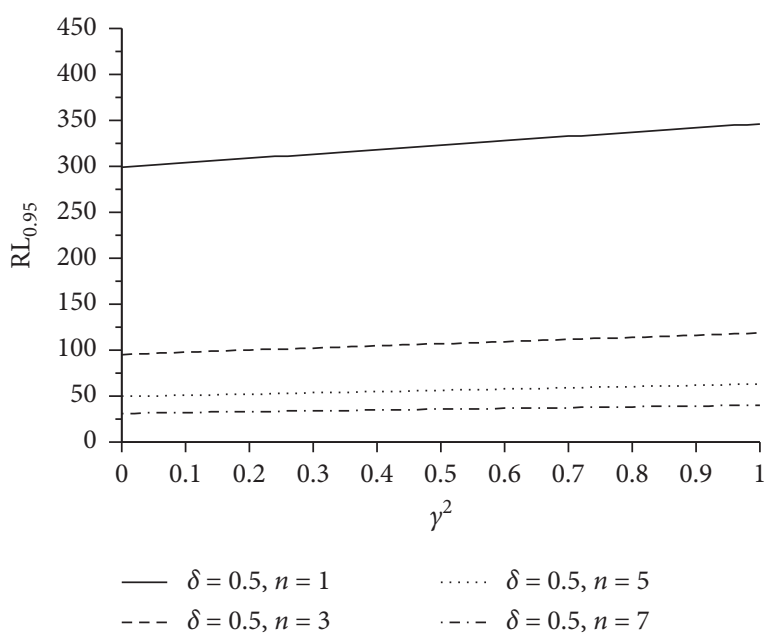

(c)

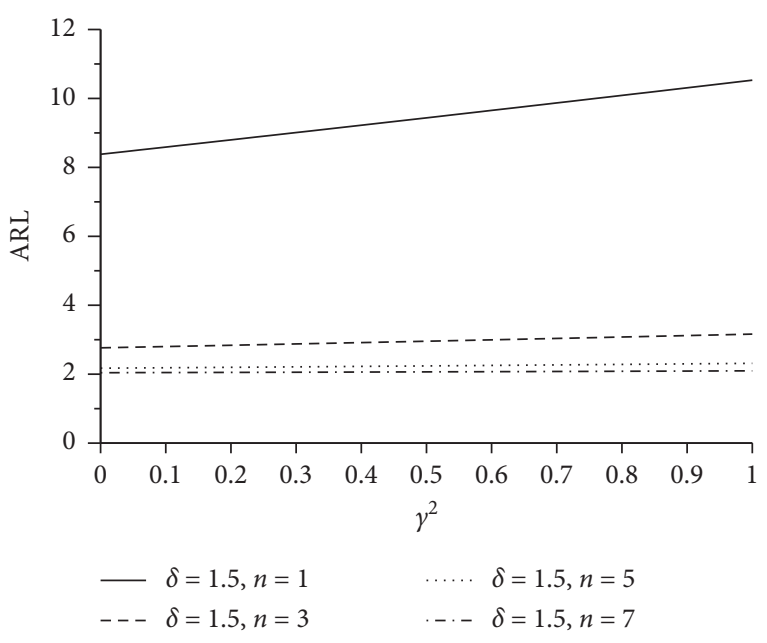

(b)

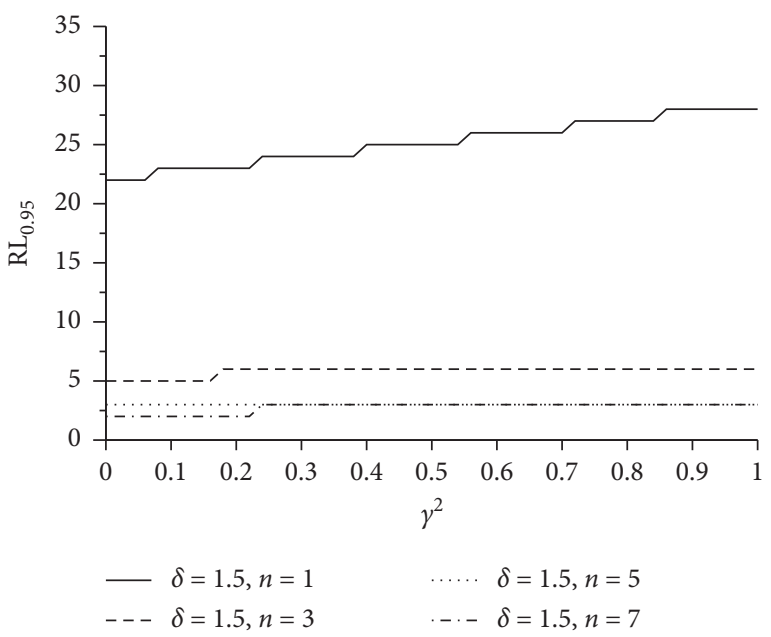

(d)

Figure 5: The effect of $\gamma^{2}$ on the run rule Shewhart $\bar{X}$ chart when $m=5, B=1, \delta \in\{0.5,1.5\}$, and $n \in\{1,3,5,7\}$.

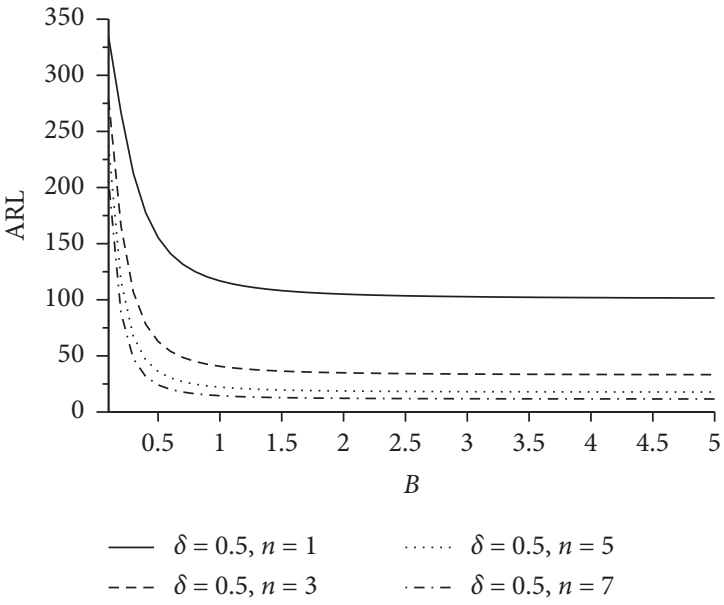

(a)

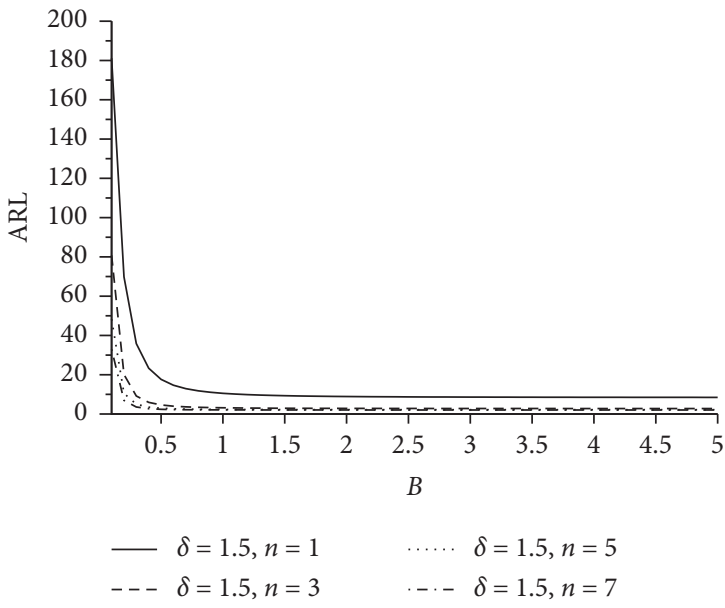

(b)

Figure 6: Continued. 


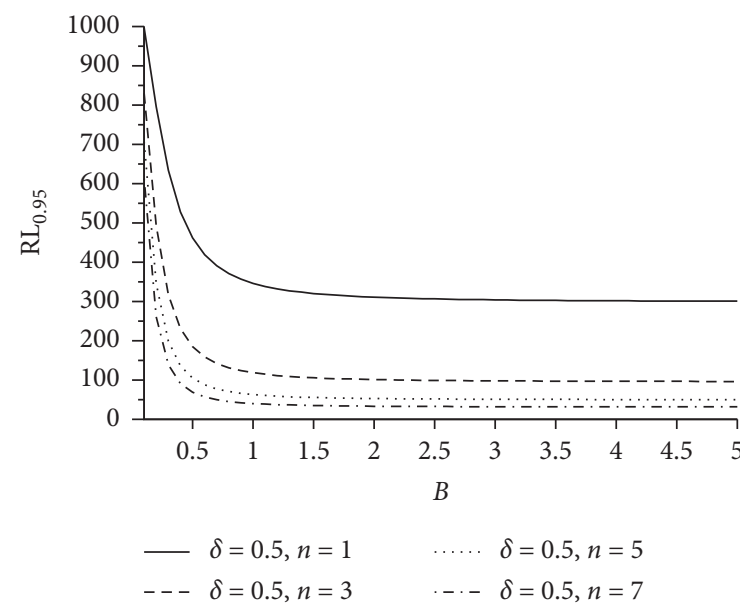

(c)

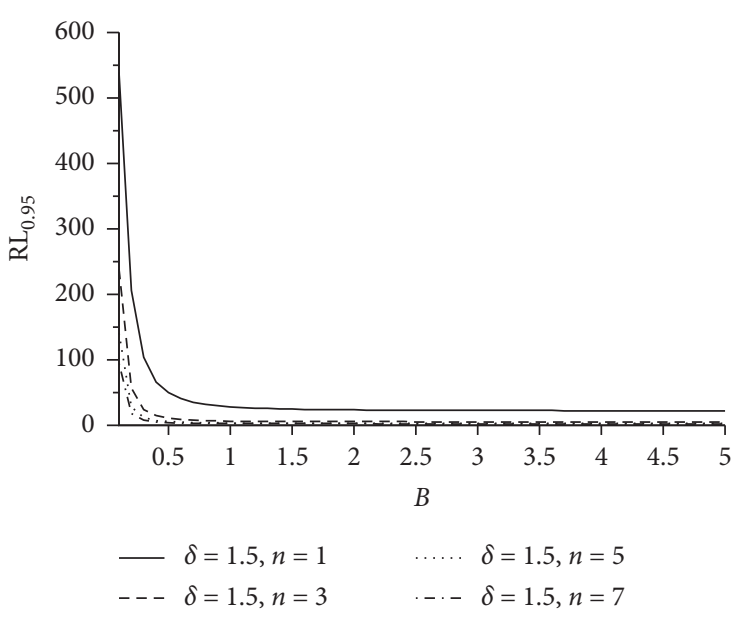

(d)

Figure 6: The effect of $B$ on the run rule Shewhart $\bar{X}$ chart when $m=5, \gamma^{2}=1, \delta \in\{0.5,1.5\}$, and $n \in\{1,3,5,7\}$.

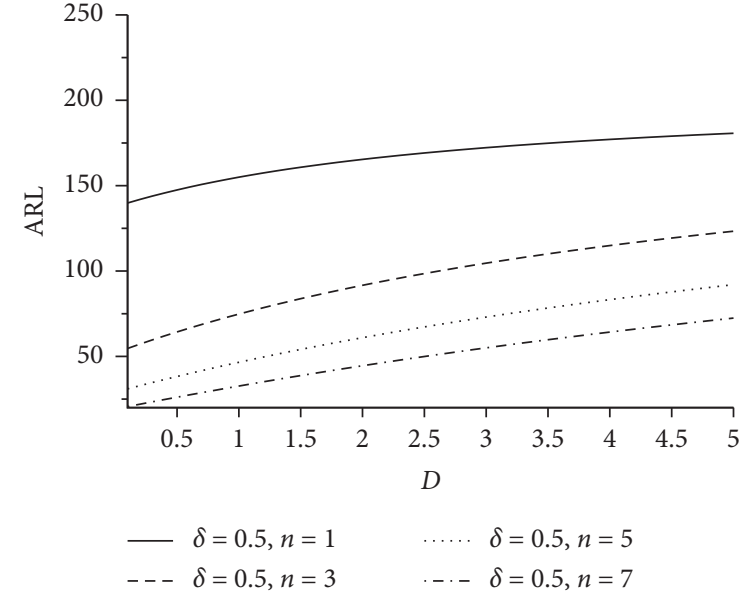

(a)

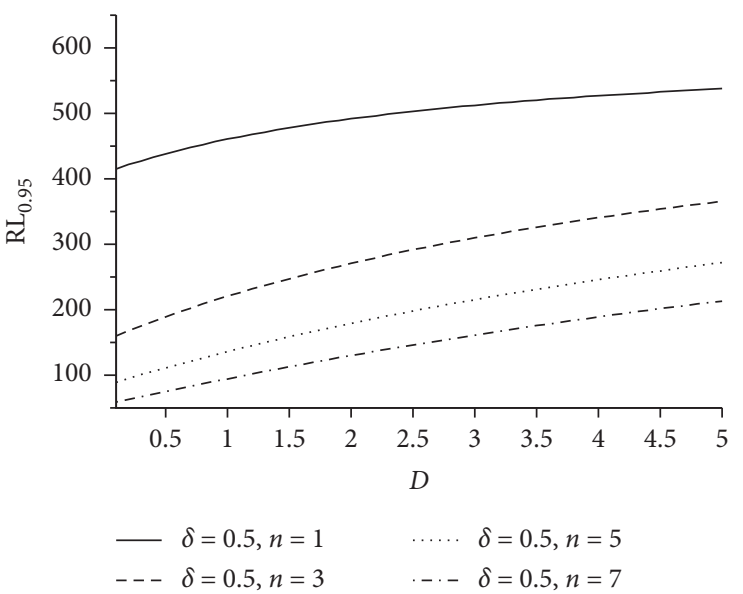

(c)

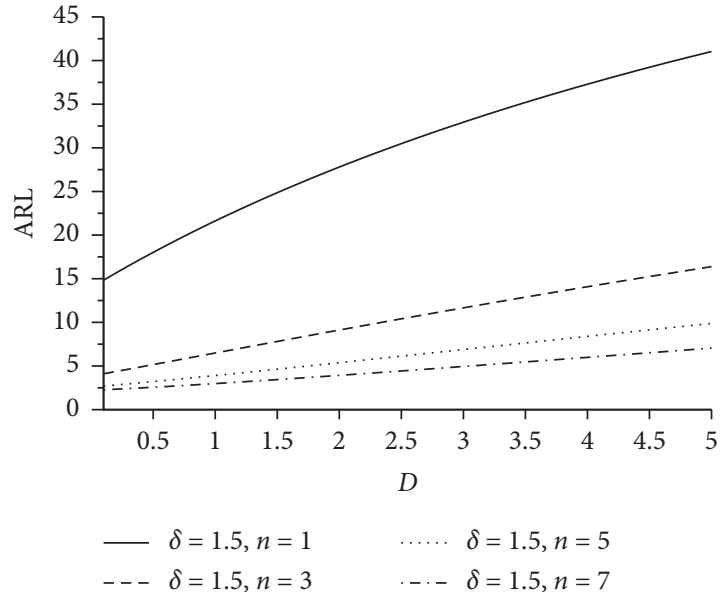

(b)

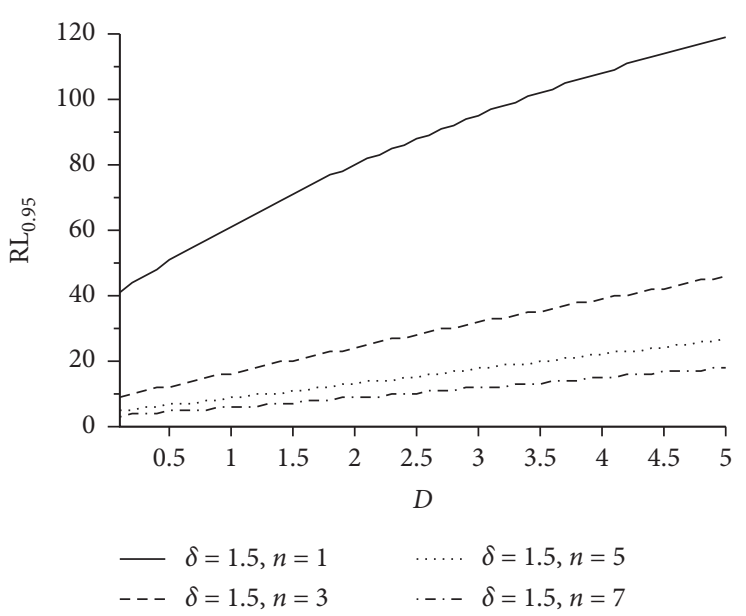

(d)

Figure 7: The effect of $D$ on the run rule Shewhart $\bar{X}$ chart when $C=5, m=1, \mu_{0}=10, \sigma_{0}^{2}=10, \delta \in\{0.5,1.5\}$, and $n \in\{1,3,5,7\}$. 
TABLE 4: 20 samples corresponding to a sequence of production.

\begin{tabular}{|c|c|c|c|c|c|c|c|c|c|c|c|}
\hline$i$ & & & & & & & & & & & $\bar{X}_{i}$ \\
\hline 1 & 125.24 & 125.35 & 125.12 & 125.15 & 123.38 & 123.13 & 124.75 & 125.38 & 126.18 & 126.50 & 125.02 \\
\hline 2 & 124.79 & 124.93 & 124.42 & 124.61 & 123.90 & 124.21 & 123.46 & 123.68 & 123.89 & 124.63 & 124.25 \\
\hline 3 & 124.96 & 124.95 & 124.40 & 124.54 & 124.93 & 124.94 & 125.54 & 125.59 & 124.96 & 124.80 & 124.96 \\
\hline 4 & 125.55 & 124.96 & 125.76 & 125.44 & 124.88 & 124.53 & 125.85 & 126.35 & 123.76 & 124.20 & 125.13 \\
\hline 5 & 124.92 & 125.01 & 123.86 & 124.27 & 124.16 & 124.29 & 124.77 & 125.29 & 125.93 & 125.52 & 124.80 \\
\hline 6 & 124.95 & 125.27 & 125.92 & 125.95 & 124.23 & 124.15 & 124.90 & 125.61 & 124.50 & 124.28 & 124.98 \\
\hline 7 & 124.16 & 124.41 & 122.80 & 123.15 & 125.76 & 124.96 & 126.34 & 126.21 & 125.04 & 125.06 & 124.79 \\
\hline 8 & 125.73 & 126.04 & 125.08 & 124.87 & 123.98 & 124.28 & 124.29 & 124.18 & 124.28 & 124.55 & 124.73 \\
\hline 9 & 125.75 & 125.63 & 124.58 & 124.41 & 125.38 & 125.07 & 123.71 & 123.78 & 124.86 & 124.73 & 124.79 \\
\hline 10 & 123.33 & 123.48 & 124.22 & 124.49 & 125.13 & 125.06 & 126.51 & 126.10 & 124.99 & 125.16 & 124.85 \\
\hline 11 & 124.29 & 124.86 & 124.67 & 125.03 & 124.78 & 125.32 & 122.70 & 122.39 & 123.22 & 122.95 & 124.02 \\
\hline 12 & 123.86 & 123.63 & 123.34 & 123.84 & 122.87 & 123.04 & 123.73 & 123.93 & 123.87 & 123.83 & 123.59 \\
\hline 13 & 125.32 & 125.12 & 123.68 & 123.48 & 123.41 & 122.97 & 124.77 & 124.00 & 123.75 & 123.73 & 124.02 \\
\hline 14 & 124.02 & 124.43 & 124.05 & 124.43 & 122.86 & 122.94 & 124.65 & 124.55 & 124.16 & 124.09 & 124.02 \\
\hline 15 & 123.93 & 123.85 & 123.93 & 123.47 & 124.47 & 124.96 & 124.45 & 124.61 & 122.82 & 122.56 & 123.90 \\
\hline 16 & 125.83 & 125.87 & 123.89 & 124.09 & 124.40 & 124.15 & 124.55 & 124.35 & 123.44 & 123.14 & 124.37 \\
\hline 17 & 125.33 & 124.97 & 124.57 & 124.37 & 123.97 & 124.29 & 124.90 & 125.24 & 124.38 & 124.16 & 124.62 \\
\hline 18 & 123.02 & 123.10 & 124.50 & 124.45 & 124.96 & 125.15 & 125.66 & 125.23 & 124.88 & 124.34 & 124.53 \\
\hline 19 & 122.93 & 123.35 & 125.18 & 124.79 & 124.12 & 124.15 & 124.18 & 124.03 & 125.04 & 125.08 & 124.28 \\
\hline 20 & 124.59 & 124.64 & 121.48 & 121.21 & 122.63 & 123.08 & 123.68 & 123.42 & 123.79 & 123.21 & 123.17 \\
\hline
\end{tabular}

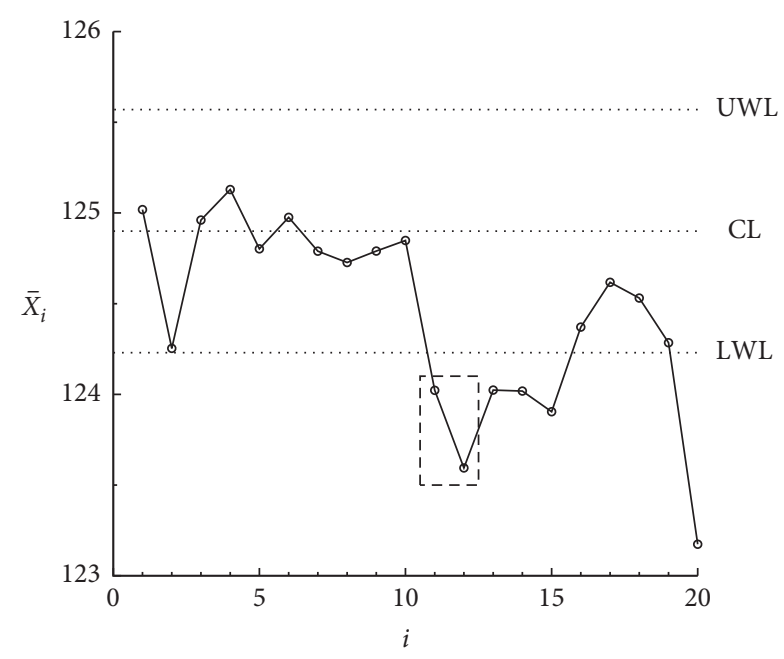

FIGURE 8: $\bar{X}$ chart with 2 -of-3 run rules corresponding to the data in Table 4.

\section{An Illustrative Example}

Similar to the research work in Costa and Castagliola [21], a yogurt cup filling process is used here to illustrate the implementation of the $\bar{X}$ chart integrated with run rules when measurement error exists. The critical quality characteristic in the filling process is the weight $Y$ of each yogurt cup. From the historical database of yogurt cup weights (Phase I), the in-control mean $\mu_{0}=124.9$ and the standard deviation $\sigma_{0}=0.76$ are estimated accurately. Moreover, an independent R\&R (repeatability and reproducibility) study has showed an estimated measurement standard deviation $\sigma_{M}=0.24$, which leads to $\gamma=0.24 / 0.76=0.316$. By fixing the parameter settings $A=0$ and $B=1$ in the linearly covariate error model, the quality practitioner decides to use Shewhart $\bar{X}$ chart integrated with 2 -of-3 run rules to monitor the process. Taking $n=5$ yogurt cups and measuring each item $m=2$ times, in a sample, the parameter $W$ of the run rule $\bar{X}$ chart can be calculated as $W=1.9293$ using equation (20). Then, the warning limits in equations (7) and (8) are given as follows:

$$
\begin{aligned}
& \mathrm{LWL}=124.9-1.9293 \times \sqrt{\frac{1}{5}\left(0.76^{2}+\frac{0.24^{2}}{2}\right)}=124.23, \\
& \mathrm{UWL}=124.9+1.9293 \times \sqrt{\frac{1}{5}\left(0.76^{2}+\frac{0.24^{2}}{2}\right)}=125.57 .
\end{aligned}
$$

In addition, 20 samples corresponding to a sequence of production (Phase II) are recorded in Table 4 . We have 10 values for each sample, i.e., the weight of $n=5$ yogurt cups weighed $m=2$ times. The mean $\bar{X}_{i}$ of these samples is presented in the right side of Table 4. In Figure 8, these mean values $\bar{X}_{i}$ with the warning limits $\mathrm{LWL}=124.23$ and $\mathrm{UWL}=$ 125.57 are also plotted. As it can be seen in the figure, the Shewhart $\bar{X}$ chart with 2-of-3 run rules actually triggers an out-of-control signal from samples 11 and 12 (shown in the frame), suggesting a downward shift in the process mean. One possible reason is that the pipe used for filling the cups is clogged.

\section{Conclusion}

The properties of Shewhart $\bar{X}$ chart integrated with run rules are investigated when errors exist in the measurement of observations in a quality characteristic. By using a linearly covariate error model, (ARL, $\mathrm{RL}_{0.95}$ ) of the chart is derived using a Markov chain approach. The simulations results show that $\left(\mathrm{ARL}, \mathrm{RL}_{0.95}\right)$ of the run rule Shewhart $\bar{X}$ chart is seriously affected by the measurement errors. With the measurement error increasing, the run rule Shewhart $\bar{X}$ 
chart's performance deteriorates. To reduce the negative effect of measurement errors, it is beneficial to measure each item in each subgroup more times and increase the coefficient $B$ in the linearly covariate error model whenever possible. Both are good alternatives to implement the run rule Shewhart $\bar{X}$ chart. It should be careful that measuring each item more times practically causes more cost.

All the results are based on the covariate error model, and it would be interesting to extend our research to different control charts with some other measurement error models.

\section{Data Availability}

All relevant data are included within the article.

\section{Conflicts of Interest}

The authors declare that they have no conflicts of interest.

\section{Acknowledgments}

This study was supported by the National Social Science Foundation of China (no. 20CRK004), Social Science Foundation of Jiangsu (no. 17GLC001), Humanity and Social Science Foundation of Ministry of Education of China (no. 19YJC630025), Key Research Base of Philosophy and Social Sciences in Jiangsu-Information Industry Integration Innovation and Emergency Management Research Center, and Excellent Innovation Teams of Philosophy and Social Science in Jiangsu Province (2017ZSTD022).

\section{References}

[1] Western-Electric, Statistical Quality Control Handbook, Western Electric Co, Rossville, GA, USA, 1956.

[2] J. J. Divoky and R. W. Taylor, "Detecting process drift with combinations of trend and zonal supplementary runs rules," International Journal of Quality \& Reliability Management, vol. 12, no. 2, pp. 60-71, 1995.

[3] C. W. Champ and W. H. Woodall, "Signal probabilities of runs rules supplementing a shewhart control chart," Communications in Statistics-Simulation and Computation, vol. 26, no. 4, pp. 1347-1360, 1997.

[4] M. Klein, "Two alternatives to the shewhart $X$ control chart," Journal of Quality Technology, vol. 32, no. 4, pp. 427-431, 2000.

[5] J. C. Fu, G. Shmueli, Y. M. Chang, and Y. Chang, "A unified Markov chain approach for computing the run length distribution in control charts with simple or compound rules," Statistics \& Probability Letters, vol. 65, no. 4, pp. 457-466, 2003.

[6] X. L. Hu and P. Castagliola, "A re-evaluation of the run rules xbar chart when the process parameters are unknown," Quality Technology and Quantitative Management, vol. 16, no. 9, pp. 696-725, 2019.

[7] X. Chew, K. W. Khaw, and M. H. Lee, "The efficiency of run rules schemes for the multivariate coefficient of variation in short runs process," Communications in Statistics-Simulation and Computation, pp. 1-21, 2019.

[8] S. C. Shongwe and M. A. Graham, "Some theoretical comments regarding the run-length properties of the synthetic and runs-rules $X$ monitoring schemes-part 1: zero-state," Quality Technology \& Quantitative Management, vol. 16, no. 2, pp. 170-189, 2019.

[9] S. C. Shongwe, J. C. Malela-Majika, and E. M. Rapoo, "Onesided and two-sided w-of-w runs-rules schemes: an overall performance perspective and the unified run-length derivations," Journal of Probability and Statistics, vol. 2019, Article ID 6187060, 20 pages, 2019.

[10] K. W. Khaw and X. Y. Chew, "A re-evaluation of the run rules control chart for monitoring the coefficient of variation," Optimization \& Information Computing, vol. 7, no. 4, pp. 716-730, 2019.

[11] X. Chew, M. B. C. Khoo, K. W. Khaw, and M. H. Lee, "An improved hotelling's $\mathrm{T} 2$ chart for monitoring a finite horizon process based on run rules schemes: a Markov-chain approach," Applied Stochastic Models in Business and Industry, vol. 37, no. 3, pp. 577-591, 2020.

[12] S. C. Shongwe, "On the design of nonparametric runs-rules schemes using the Markov chain approach," Quality and Reliability Engineering International, vol. 36, no. 5, pp. 1604-1621, 2020.

[13] J.-C. Malela-Majika and E. Rapoo, "Distribution-free cumulative sum and exponentially weighted moving average control charts based on the Wilcoxon rank-sum statistic using ranked set sampling for monitoring mean shifts," Journal of Statistical Computation and Simulation, vol. 86, no. 18, pp. 3715-3734, 2016.

[14] J. C. Malela-Majika, E. M. Rapoo, A. Mukherjee, and M. A. Graham, "Distribution-free precedence schemes with a generalized runs-rule for monitoring unknown location," Communications in Statistics-Theory and Methods, vol. 49, no. 20, pp. 4996-5027, 2020.

[15] X. L. Hu, P. Castagliola, J. L. Zhong, A. A. Tang, and Y. L. Qiao, "On the performance of the adaptive EWMA chart for monitoring time between events," Journal of Statistical Computation and Simulation, vol. 91, no. 7, pp. 1175-1211, 2021.

[16] Y. Ali, A. Shadman, and A. Amiri, "A novel run rules based MEWMA scheme for monitoring general linear profiles," Computers \& Industrial Engineering, vol. 152, Article ID 107031, 2021.

[17] K. W. Linna and W. H. Woodall, "Effect of measurement error on shewhart control charts," Journal of Quality Technology, vol. 33, no. 2, pp. 213-222, 2001.

[18] K. W. Linna, W. H. Woodall, and K. L. Busby, "The performance of multivariate control charts in the presence of measurement error," Journal of Quality Technology, vol. 33, no. 3, pp. 349-355, 2001.

[19] P. Maravelakis, J. Panaretos, and S. Psarakis, "EWMA chart and measurement error," Journal of Applied Statistics, vol. 31, no. 4, pp. 445-455, 2004.

[20] P. E. Maravelakis, "Measurement error effect on the CUSUM control chart," Journal of Applied Statistics, vol. 39, no. 2, pp. 323-336, 2012.

[21] A. F. B. Costa and P. Castagliola, "Effect of measurement error and autocorrelation on the $\bar{X}$ chart," Journal of Applied Statistics, vol. 38, no. 4, pp. 661-673, 2011.

[22] X. L. Hu, P. Castagliola, J. S. Sun, and M. B. C. Khoo, "The effect of measurement errors on the synthetic X chart," Quality and Reliability Engineering International, vol. 31, no. 8, pp. 1769-1778, 2015.

[23] X. L. Hu, P. Castagliola, J. S. Sun, and M. B. C. Khoo, “The performance of variable sample size $\bar{X}$ chart with 
measurement errors," Quality and Reliability Engineering International, vol. 32, no. 3, pp. 969-983, 2016.

[24] M. R. Maleki, A. Amiri, and P. Castagliola, "Measurement errors in statistical process monitoring: a literature review," Computers \& Industrial Engineering, vol. 103, pp. 316-329, 2017.

[25] X. B. Cheng and F. K. Wang, "The performance of ewma median and cusum median control charts for a normal process with measurement errors," Quality and Reliability Engineering International, vol. 34, no. 2, pp. 203-213, 2018.

[26] S. C. Shongwe, J.-C. Malela-Majika, and P. Castagliola, "The new synthetic and runs-rules schemes to monitor the process mean of autocorrelated observations with measurement errors," Communications in Statistics-Theory and Methods, 2020.

[27] H. D. Nguyen, K. P. Tran, G. Celano, P. E. Maravelakis, and P. Castagliola, "On the effect of the measurement error on shewhart $\mathrm{t}$ and ewma $\mathrm{t}$ control charts," The International Journal of Advanced Manufacturing Technology, 2020.

[28] H. D. Nguyen, K. P. Tran, and K. D. Tran, "The effect of measurement errors on the performance of the exponentially weighted moving average control charts for the ratio of two normally distributed variables," European Journal of Operational Research, vol. 293, no. 1, pp. 203-218, 2021.

[29] M. Thanwane, J.-C. Malela-Majika, P. Castagliola, and S. C. Shongwe, "The effect of measurement errors on the performance of the homogenously weighted moving average $\bar{X}$ monitoring scheme," Transactions of the Institute of Measurement and Control, vol. 43, no. 3, pp. 728-745, 2021a.

[30] M. Thanwane, J.-C. Malela-Majika, P. Castagliola, and S. Charles Shongwe, "The effect of measurement errors on the performance of the homogenously weighted moving average $\bar{X}$ monitoring scheme with estimated parameters," Journal of Statistical Computation and Simulation, vol. 91, no. 7, pp. 1306-1330, 2021.

[31] F. F. Gan, "An optimal design of EWMA control charts based on run length," Journal of Statistical Computation and Simulation, vol. 45, no. 3, pp. 169-184, 1993.

[32] M. B. C. Khoo, V. H. Wong, Z. Wu, and P. Castagliola, "Optimal design of the synthetic chart for the process mean based on median run length," IIE Transactions, vol. 44, no. 9, pp. 765-779, 2012. 